\title{
Analyses of the Theoretical and Conceptual Frameworks for Tourism Development of Cultural Landscape
}

\author{
Olasunmbo, Adhuze* \\ Department of Architectural Technology, Federal Polytechnic, Ado-Ekiti \\ Joseph, Fadamiro \\ Department of Architecture, The Federal University of Technology, Akure \\ Dorcas, Ayeni \\ Department of Architecture, The Federal University of Technology, Akure
}

\begin{abstract}
The exposure of the cultural landscape to tourism activities puts a lot of pressure on the common heritage of man with a possibility of the loss of the attractions to the landscape. This often happens because the necessary attention to the development of such fragile touristic sites are absent thus exposing them to stages of deterioration. This paper is a review of theoretical issues related to the development and sustainability of the cultural landscape. Through the review of literatures, previous models such as, General System Theory (Cuervo, 1967), Cultural landscape Management framework (2006), Diamond Model for sustainable tourism (2017), and The Ethical tourism model (2008), a conceptual framework for the sustainability of the cultural landscape was developed. The study, however, provides useful information for the development and conservation of a cultural landscape through a framework that can inform policy makers in the tourism industry.
\end{abstract}

Keywords: Cultural Landscape; Framework; Models; Tourism Development; Sustainability.

DOI: $10.7176 / \mathrm{JTHS} / 59-02$

Publication date:October $31^{\text {st }} 2021$

\subsection{Introduction}

The interaction of man with the environment is an occurrence that has existed since the creation of man himself on earth and this has grown for centuries with man having different effects on the natural environment. Effects of man on the natural environment have been wide and varied, from man providing the basic necessities of life for himself like food and shelter to the non-basic ones such as travel, sight-seeing, recreation, tourism and a host of others. Giving the environment a holistic description, after examining it from different fields of profession, Isife (2017) described it as all physical, non-physical, external, living and non-living situations surrounding an organism that determine its existence, development and survival at a particular time. It encompasses constantly interacting sets of physical (natural and man-made) elements and non-physical, living and non-living (social, cultural, religious, political, economic) systems, which determine the characteristic features, growth and sustainability of both the component elements of the environment and the environment itself (Johnson,1992; Muoghalu, 2004).

This relationship with the environment birthed the cultural landscape which according to the United Nations Education and Socio-Cultural Organization (UNESCO) is a cultural property that represents the "combined works of nature and man". It is illustrative of the evolution of human, society and settlement over time, under the influence of the physical constraints and/or opportunities presented by their natural environment and of successive social, economic and cultural forces, both external and internal" (UNESCO, 2008, Kirdsiri, 2011, Fadamiro and Adedeji, 2015). The definition that the United States National Park Service uses for cultural landscapes further confirms the international agreement that it is: 'A geographic area, including both cultural and natural resources and the wildlife or domestic animals therein, associated with a historic event, activity, or person exhibiting other cultural or aesthetic values' (Birnbaum, 1999). Each people have a specific relation, physical and associative, with their environment, which is enshrined in culture, language, livelihood, sense of being and identity. More so, it is inseparable from its relationship with the land (UNESCO and WHC, 2013). The term "cultural landscape" embraces a diversity of manifestations of the interaction between humankind and its natural environment and the environment has become a fascination to people who value it.

Findings from literature is indicative of the fact that research on tourism is abundant and up-to-date and increasing but for the cultural landscape, it is still far from what it should because the concept is still relatively new and research work are far-between. While conservation is a global phenomenon, the environment and its challenges are basic platform for conservation as it provides a fundamental solution to the problems of degradation and sustainability.

Mason (2003) posited that, the environment is a tourist attraction itself being a key factor of tourism, although, this could be complex, both tourism and environment are intertwined. Tourism benefits from a good 
quality environment requiring the environment to be protected and maintained. Ayeni (2012) stated that the environment is a common resource to all and it plays a very important role in tourism as environmental quality determines the level of patronage of a tourist destination. GhulamRabbany, Afrin, Rahman, Islam and Hoque (2013) affirmed that tourism industry is directly related to the environment and the quality of the environment, both natural and man-made, is essential to tourism. However, the relationship of tourism with the environment is complex. It involves many activities that can have adverse environmental effects. (Sunlu, 2003)

The environment in which man lives is a gift of nature to him and on daily bases man interacts with his environment to provide for himself and his dependents for basic needs of life and for survival. But because of man's daily interactions with the environment, he causes damage due to his negligence and lack of alertness to the demands of the environment for restoration and today, the damages are somewhat irreversible. Siyanbade (2007); Koncul (2008) and Isife (2017) all supported this view when they affirmed that most human activities affect the environment and causes changes which have repercussions. Unfortunately, despite the results noticed daily of the degradation of the environment, man still continues to depend solely on his environment for sustenance thereby further depleting the resources and causing greater hazard to the environment without putting in place measures for restoration.

Nigeria is a nation blessed with abundance of rich environment to experience for tourism (Jiboku and Jiboku, 2010; Yusuff and Akinde, 2015; Ejikeme, Okpoko, Okpoko and Diminyi 2020). Nigeria is rich in both natural and cultural environment spread all around the country (Elochukwu, 2015), they exist as flora, fauna and geomorphic features in the natural/ecological sphere and as artifacts, customs, festivals, worship sites, values, ideologies, dress-patterns, traditional monuments, architectures and other artifacts which are cherished (Jiboku and Jiboku, 2010; Onyima, 2016). But there is a point of connection of both the natural and cultural environments, and that is the cultural landscape and that being a heritage site requires more attention due to its delicate nature for preservation of both tangible and intangible core.

The challenge is the gap which exist in the development of the peoples' heritage for the advantage of all and for the preservation of the site for the future generation. Sustainable tourism should be the goal of any tourism venture so that tourism does not impinge on the environment, ecology and the erosion of historical artifacts which are the main reason for visits to a cultural landscape and that is the focus of this research.

\subsection{Literature review}

\subsection{Tourism and cultural landscape}

Several studies have proven the profitability of tourism on the global stage and with the increase in tourism and knowledge of its benefits, protected areas can be consciously developed and maintained to harness that benefit (Oyelowo, Chima, and Oladoye, 2010). A developing country as Nigeria can leverage on tourism for income on foreign exchange, job creation and above all, a means of diversification form over-dependence on oil (Jiboku and Jiboku, 2010; Ayeni, 2012; Ayeni, 2013). This can be achieved where the tourism industry is consciously developed and the environment protected to support the endeavor, harnessing its rich cultural heritage to support tourism. Nature has provided the raw materials, it is the duty of man to develop and harness it for the advantage of all, that is, the human and the environment which they live in. Since the culture of a people has both geography and history as spatial and temporal entities, respectively, and the domains of space and time are essential to understanding the civilization of any group of people (Fadamiro and Adedeji, 2015), and has now become an aspect of tourism that relies more on using the natural and cultural relics of a people to promote tourism in their area for a better economic growth and sustainability (Nwankwo, 2015) but not without its own cahllenges.

The development of tourism on a cultural landscape does not seem as easy as it is on a regular tourist destination because of the uniqueness of cultural landscape. Cultural landscape is considered to be a landscape which has been transformed by man as a result of civilizational development (Myga- Piatek, 2013). It is the evolutionary reflection of growing human skills and abilities to use and transform the environment (Anreychouk, 2008; Zhou, 2016). Nora, Mechtild, and Pierre-Marie, (2009) noted that the cultural landscape embraces a diversity of manifestations of the interaction between humankind and its natural environment. It is a component of accumulated resources, which could be immaterial or material, that people inherit, employ, transmute, add to and transmit (Leach, 2000, Escudero, 2014). The long-time span of culture on the cultural landscape qualifies it as a heritage (Adeyemi and Oyinloye, 2020) and as a protected site under the 1972 world heritage convention (UNESCO, 2008). The World Commission on Protected Areas (WCPA) defines a protected area as an area of land and/or sea especially dedicated to the protection and maintenance of biological diversity, associated cultural and natural resources, and managed through legal and other effective means (IUCN, 1994). But Oyelowo, Chima, and Oladoye (2010) noted that there is a growing recognition that many of the world's protected areas are not secured and that a significant proportion of these are actually being degraded and destroyed, cultural landscapes not exempted.

The opening of cultural landscape sites to tourism comes with great worries and anxieties for the 
sustainability of the environment with the effect of mass tourism. The major concern then is the environmental sustainability of tourism on the cultural landscapes which has to do with the preservation of the natural environment. Environmental sustainability has to do with the physical environment, which arose out of the complexities of interrelated issues facing environmental and developmental problems facing humanity (Rohinson, 1996). These problems include; increasing degradation of the global environment, deterioration and depletion of natural resources, excessive consumption, rising population pressure, poverty and pollution amongst others (Agbebaku, 2015). It therefore, requires environmentally sensitive attitudes and holistic resource management which means the capability of nature or the total environment to continue over time, enhancing the quality and conserving the environment from any negative impacts of tourism.

Environmental sustainability does not require a loss in the quality of life but does require a change in mind (Glamberdine \& Lonpenske, 1993; Arora, 2018), and in values toward the physical environment which should enhance the quality of life while conserving nature (Bolívar, Daponte, Rodríguez, \& Sánchez, 2010). Therefore, the principle of environmental sustainability is aimed at addressing the problems of environmental degradation and improving the quality of life by supporting development that is sustainable in nature. These kinds of developments will not only look at the current benefits but will consider it against the preservation of the environment for the future to also benefit.

\subsection{Tourism challenges in the Cultural landscape sites}

Cultural tourism has brought employment to millions, often in remote parts of the world. It has provided inspiration, recreation and enjoyment to countless visitors (Timothy, 2011). But it has also destroyed and polluted unique, fragile and pristine environments, threatened local cultures, and devalued the heritage characteristics that make it both of outstanding universal value and a desirable tourist destination due to nondevelopment and a lack of protection and conservation plans by the development authorities in charge of the sites (Elochukwu, 2015; Diminyi and Okpoko 2017). In the opinion of Benson (2014), when visits are made to cultural sites, due to the experiences of the visit, tourists are easily motivated to return to the same destination, to stay in one place longer or to visit minor destinations instead. Unfortunately, there is the challenge of many adverse impacts, especially in respect of the environment, where carrying capacity is exceeded at major heritage sites and sustainability becomes an uphill task.

Haenreat (2009) and Adillion (2019) noted that cultural landscapes can be easily disfigured because there is no conscious effort by stakeholders to protect it. Facilities present at the cultural landscape sites become issues for development and maintenance as they may not meet required standards, which are supposed to form pull factors for the sites, and ensure the conservation of its tangible and intangible essence. This is because there has been little or no attention paid to their development nor sustainability by the stakeholders, (governments, developmental organizations and local residents) unfortunately. As a result, there seem to be degeneration, which does not make such a site appealing to tourists for visit. (Dalat, 2010; Tunde 2012 and Ojo 2014). This has generated problems in terms of conservation of the cultural landscape, which also impinge on the appreciation of the site because a tourism site which ought to be self-sustaining is not.

Cultural landscapes will be threatened by specific climate change phenomena and impacts, requiring management decisions and actions that respond to those phenomena (Melnick, Burry-Trice, and Malinay, 2015). Climate change is an offshoot of environmental degradation which is basically caused by man (Adhuze and Ayeni, 2019). Climate change affects basically the environment and, in most cases, causes environmental degradation. Environmental degradation has been caused by human activities such as the burning of fossil fuel for heat and energy, deforestation, the release of harmful chemicals into the atmosphere from industries (NRC, 2010). The effects of this are found in almost all sectors of the society which includes to a large extent, the tourism industry which depends largely on the environment. Bio-diversity is a major point of attraction to natural sites and there is the potential of a loss of it due to environmental degradation, which will also translate to a loss of tourism potential of such site (GhulamRabbany et al., 2013).

Landscapes are cultural products of power, identity and belief semiotically encoded in the built environment (Low, 2000; Fadamiro \& Adedeji, 2012). They are 'integrative and visible socio-ecological systems of natural, physical, cultural, social, and aesthetic properties' across different spatial- temporal scales (Landscape Europe, 2015). Knowledge of the past is necessary for a systematic understanding of a people's unique present, and as a launching pad for molding a prosperous future for themselves (Matero, 2014). But due to rapid globalization and urbanization, traditional cultural tour sites are experiencing challenges in protecting city memory and inheriting regional culture, failing in fulfilling its purpose (Zhou, 2016). Fadamiro, Adedeji, \& Ibrahim, (2013) also posited that the onslaught of urbanization, modernization, and civilization, the cultural value system of the landscapes have been delimited and many of the "sacred" spaces have been encroached upon for building purposes in some traditional urban cores (Fadamiro and Adedeji, 2015). In Nigerian cities, the pace of socio-economic activities has led to urban challenges and deteriorations which are being extended to the cultural landscape especially those in the urban centre. Some of these challenges include; flood, deforestation, landslides, overpopulation, air 
pollution, climate change, global warming and loss of biodiversity which stand as threat to the cultural landscape. Most cities are witnessing high rate of environmental challenges and are rated among urban areas with the lowest livability index in the world (Agbebaku, 2016).

Tourism pressures represent one of the greatest threats to the settings of monuments and sites and heritage places inevitably attract high levels of tourism interest and activity (Shah, McHarry and Gardiner, 2002; Adillion, 2019). World Heritage listing is almost guaranteed to result in a huge increase in tourism interest since they are listed based on the universal values which they habour, Evidently, as tourism grows, the resource use threatens to become unsustainable and with a degraded physical environment, the destination is in danger of losing its original attraction (Mehta, 2013). The challenges which the direct impact of tourism imposes, if well managed can be balanced off by the positive impacts (Davies and Cahill, 2000) These are a few challenges that interpose the cultural landscape sites upon which tourism is developed, these challenges have the possibility of erasing the common heritage as time goes by. It is therefore becoming imperative for all to see the development of the cultural landscape as a duty, otherwise, such landscapes will soon become a thing of the past in no distant time and generations yet unborn will not find records of their origin or histories of the past to relate with.

\subsection{Theoretical Framework for sustainable tourism development}

The models and theories adopted in this study documented the relevant issues relating to sustainable tourism development. The model and theories identified from the literature include the General System Theory (Cuervo, 1967), Cultural Landscape Management Framework (2006) Diamond Model for sustainable tourism (2017), and The Ethical tourism model (2008).

\subsubsection{The general system theory}

General systems theory, is multidisciplinary in nature and due to its versatility, fits well into tourism which is an activity that encompasses other systems to flourish (Cuervo, 1967; Molina, 1997 and Beni, 2001). It was originally created by a biologist Ludwig von Bertalanffy (1901-1972) and the categories of thoughts could be applied in different sciences (Lohmann and Panosso-Netto, 2017). This general system theory was first used in the field of tourism by Cuervo (1967), is a large set composed of subsets such as transportation, lodging, travel agencies, gastronomy industry, entertainment centres and other commercial establishments and services. Although, these subsets could stand individually, they could also be harnessed as a whole and that is why they fit into the general system model. Molina (1997), saw tourism as a system with subsystems which include Superstructure, demand, attractions, equipment and facilities and the host communities as parts or subsystems that interact to achieve a common goal.

The superstructure includes public and private sector organizations; laws, regulations, plans, and programmes which provide the enabling environment for tourism to thrive. Infrastructure on the other hand, and the services, necessary to meet the needs of tourists and increase satisfaction during their stay at the destination such as airports, roads, water supply networks, sewage and telephones. The attractions being the natural and cultural magnet that draw people for tourism. Infrastructure and facilities are hotels, motels, campgrounds, trailer parks, restaurants, cafes, travel agencies, pools and tennis courts, among others and the hosting community which is the local residents directly and indirectly linked to tourism (Lohmann and Panosso-Netto, 2017).

Beni (2001) presented his tourism system as an open system that can influence and be influenced by the other systems with which it interacts (Lohmann and Panosso-Netto, 2017). Building up on the previous discuss merged with subsets from the previous discussion, analysed the system as composing of three sets: Environmental relationships, which are composed of cultural, social, ecological and economic subsystems. The structural organization, which consists of the superstructure and infrastructure subsystems. And operational actions, which contain the dynamics of the tourism system which include supply, market, demand, production, distribution and consumption subsystems showing its inter-relationship as put in figure 1. Jakulin (2017) applied the general system theory with its internal elements: where tourism market meets the demand and supply, intermediaries, supporting institutions and tourists flow, showing interrelations and role of a triplet tourism system, tourism decision-maker(s) and tourism model. This theory will also be applied in this study to give clear evaluation of the basis of tourism and the relationship between the environmental relationship and the structural organization. 


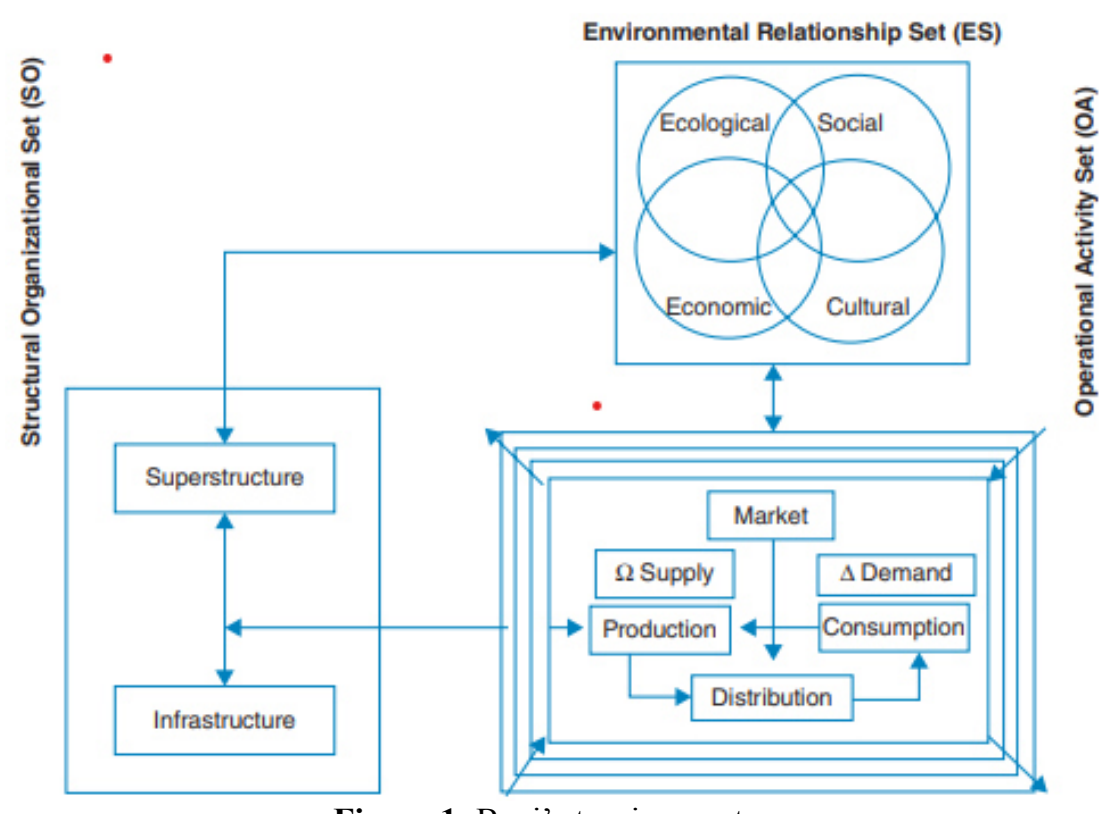

Figure 1: Beni's tourism system

Source: Beni (2001)

\subsubsection{Cultural Landscape Management Framework}

The cultural management plan according to UNESCO, is a systemic process which provides a holistic and continuous mechanism for the identification of threats and opportunities, managing and promoting the cultural landscape and provides future courses of action for the management of the site. Management plans as posited by Nora, Mechtild, and Pierre-Marie, (2009) identified values and property characteristics, establish the management objectives to be met, and indicate the actions to be implemented. Cultural landscape management plan identifies as significant for an integrated and holistic approach to the management of cultural landscapes, which have direct effects on environmental, social and economic sustainability, and contribute to society in terms of quality of life and well-being (Milan, 2016). The development of a management plan is therefore an important tool for creating agreement among stakeholders and the general public for implementation and ongoing management activities on a cultural landscape, the management is an essential activity geared to protect and conserve the heritage and the framework is a cycle of activities revolving around all stakeholders to the cultural landscape as seen in figure 2.

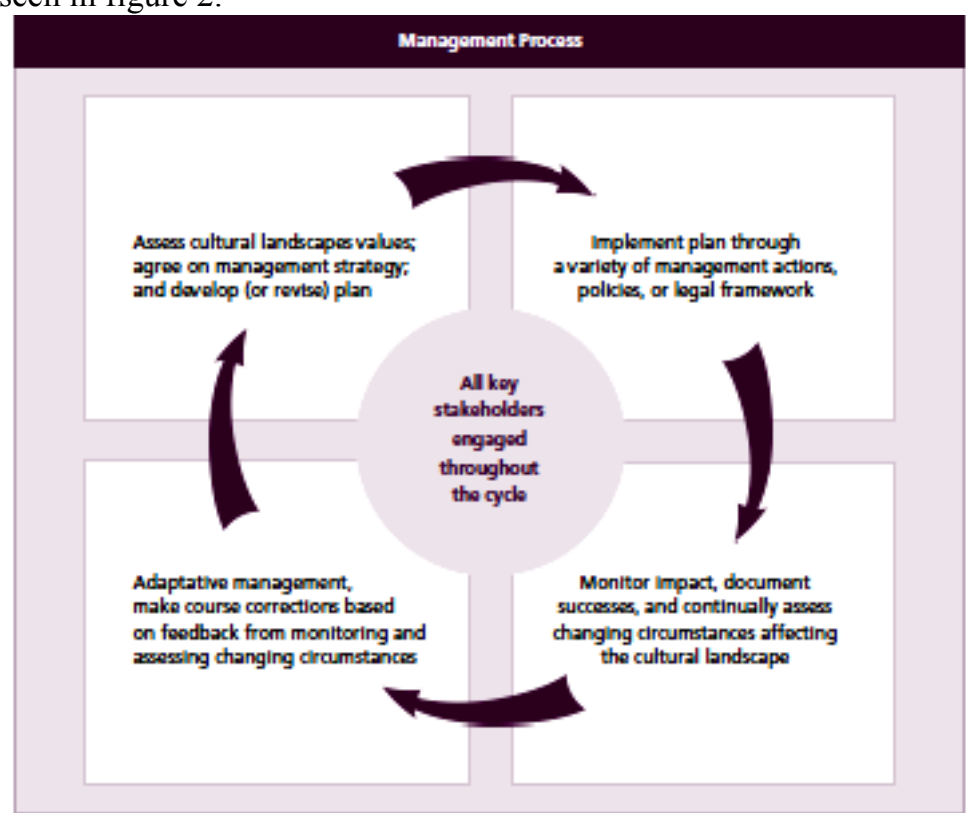

Figure 2: Cultural landscape management framework. Source: UNESCO paper 26

2.2.3 The Ethical Tourism Model (2008)

Ethical tourism model (Speed, 2008) is the 'tourism in which all stakeholders involved apply principles of good 
behaviour (justice, fairness, and equality) to their interactions with one another, society, the environment, and other life forms.' (Lovelock and Lovelock 2013). Speed (2008) opined that, ethical tourism is not a type of tourism in and of itself, but a concept that is present in other various tourism forms and segments. He further posited that ethical tourism should involve stakeholders, the environment, economic and social issues, only then can tourism be called ethical tourism. According to Fennell (2014) the history of ethics in tourism is relatively short and this began by the early 1990s when tourism scholars started turning their attention to ethical tourism due to the influence of two major events. The first was the 1992 International Association of Scientific Experts in Tourism Congress held in Paris, conference which proposed the creation of a commission to deal with ethical problems in tourism. The second event was the 1992 Rio Earth Summit (Agenda 21), and a third was the 1982 online conference on tourism which identified ethical issues challenging the sector and the issues discussed included both the negative impacts of tourism and how they could be minimized by everyone involved in the field of travel and tourism (Netto, 2017).

According to the model, ethical tourism is conscious of the whole arms of sustainability along with the forms of tourism. It expects that 'ethical tourists respect their hosts: by treading softly on the environment; by being educated about the culture; by ensuring their stay returns fair, economic benefits, and by ensuring all decision-making with all tourism's stakeholders is socially responsible' (Speed, 2008)

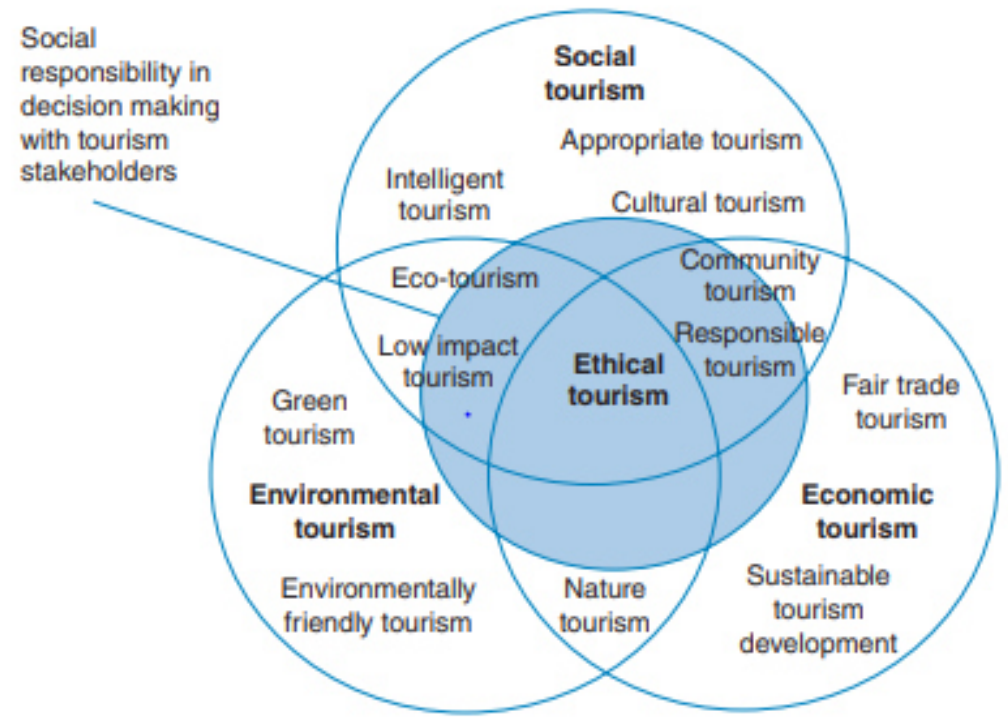

Figure 3: Ethical Tourism Model (2008).

\subsubsection{Diamond Model of Sustainable Tourism}

Source: Lohmann and Panosso-Netto, (2017)

The diamond model (Adillion, 2019) is a sustainable tourism development model that is designed to serve as a tool for Development Managers to provide independent information to support unpopular decisions of generally protecting a tourist destination (Adillion, 2019). This includes restricting the number of visitors for the sake of a sustainable development of tourism on a tourist site. The objective of such decisions has to be the achievement of an adequate development of the tourism activity that does not jeopardize the future of the tourism destination itself, considering the carrying capacity of the tourist site. Carrying capacity is described as the maximum number of people that may visit a tourist destination at the same time, without permanent natural/physical deterioration of the area's ability to support recreation and without appreciable impairment of the visitors' recreational experience (UNWTO, 1981; Miguel, 2017). This will drastically reduce the risk of destructions, defacement, vandalism, theft/smuggling activities on the site (Nwakwo, 2015). The diamond model has seven key elements that need to be taken into consideration for the sustainable development of tourism as well as the relationships among them. As seen in Figure 4, the model considers seven elements as important in the development of a tourist site; Demand Management (DM), Destination Management Organization (DMO), Local Community (LC), Smart destination (SD), Seasonal management (SM) Tourist experience (TE) and Carrying capacity (CC) (Adillion, 2019). According to the model, the seven relevant elements were arranged in a manner that the key three elements; LC, TE and CC are linked together on one side and the other three elements linked on the other, recognized as ways of action, that is DM, SD and SM leaving the body responsible of the destination attraction (DMO) in the middle as the energy or goal dispersal point, yet all are interconnected. The diamond model was arranged in a way that the contribution of the seven elements converge to give a sustainable tourism destination, which is the pursued goal. 


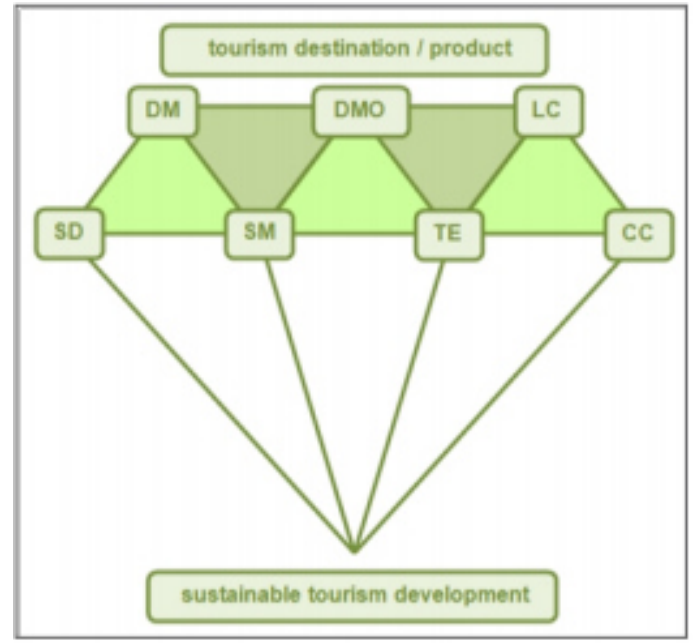

Figure 4: Diamond: A Sustainable Tourism Model.

Source: Adillón (2019)

\subsection{Methodology}

The research is based on a critical review of the current issues in tourism development and the challenge of sustainability of cultural landscapes. Advanced literature review was done to look at various tourism issues relating to the sustainability of the landscape viz-a-viz its carrying capacity, stakeholders involvement and other facilities that are meant to facilitate a worthwhile experience of tourism while still protecting it. An information portal has been used to identify relevant catalogues, reference databases, citation databases, journals and conferences to recognize potential studies/articles for the review. Detailed review was conducted on the relevant literatures found and inferences were drawn from them to draw up the framework that was arrived at for this study.

\subsection{Discussion of findings}

This study developed the cultural landscape sustainability (CLS) framework to emphasize the value of developing the cultural landscape for tourism in a sustainable way. Previous studies confirmed that the cultural landscape when developed, can boost tourism which resultantly improve the socio-economic environment, the quality of life and preserve the heritage of the people for the future generations. (Nora, Mechtild, and PierreMarie, 2009; Jiboku and Jiboku, 2010; Tosun, 2010; Ayeni, 2012; Fadamiro and Adedeji, 2015). They posited that the development of the cultural landscape for tourism will encourage a consistent patronage all over the world and create a responsible tourism environment for all users of the site. The consistent patronage of the cultural landscape and its conservation are paramount issues that require great attention to achieve sustainable tourism on the cultural landscape. If the conditions of the facilities put on and around the site are perceived to be ideal for tourism development, it will be a major step to the goal which is to encourage and promote responsible tourism on the site. Environmental challenges such as flood, water pollution, waste disposal, deforestation are major issues that could also deter the development of tourism on the site (Adhuze and Ayeni, 2019) but these can be controlled where all stakeholders to the cultural landscape are involved, feel involved and committed to the goal for its physical development and for responsible tourism on the heritage site.

Quite significantly, a wide range of literature examined in this research are based on findings from the developed countries, which may not be totally applicable in the developing country as such but allows research validation and references usage. It also highlights possibilities of drawing areas of common grounds and some of the findings could be applied to addressing tourism and environmental challenges on a cultural landscape. This becomes expedient because there is currently very limited research that has been done to discover the wealth laden in the cultural landscape as tourist destination in the developing nations and especially Nigeria.

Nevertheless, there is the need to understand how environmental challenges affect tourism and the cultural landscape. Studies have validated that environmental challenges can cause serious destruction and disruption in and on the environment (Hamzah et al, 2012; GhulamRabbany et al., 2013) and affect the daily lives of humans. Although, in most cases humans have been the cause of the challenges of the environment occasioned by the use and attitude to the environment (NRC, 2010, Adhuze and Ayeni, 2019). This study equally considered how to ameliorate the environmental challenges on the cultural landscape to boost tourism and one major way of doing that is considering the carrying capacity of the cultural landscape. 


\subsection{The proposed framework}

The proposed framework for this study termed cultural landscape and tourism sustainability framework, is hinged on developing the cultural landscape for tourism bearing the conservation of the site in mind, without depleting the essence of the cultural landscape. Sustainability of the cultural landscape is at the core of this framework as it is reflected in figure 5, to ensure that even when tourism is fully developed on the site, the pressure of tourism and tourists' activities will not deplete the original essence of the cultural landscape, this is, the carrying capacity of the cultural landscape will be bear in mind. Also, conservation will not only preserve the essence of the site but also encourage responsible tourism by the type of activities that tourists are allowed to partake on the landscape, this is because minimal stress is required for the site and its resources because of the natural tangible and intangible attributes it bears. Therefore, passive activities are required on the site to protect the flora and the fauna and maintain the sacredness of the heritage site.

The framework proposed in figure 5 also considered infrastructure that could support tourism on a cultural landscape, such facilities that aid the experience of the tourists and provide necessary information and support to all categories of tourists. This is because the tourists' experiences determine their perception of the tourist site and has a large impact on tourism development on such site. This was also supported by Panasuik (2007) that the visit of tourists to a site is necessary so that the infrastructures could create development for the region in which the site is located, since tourism infrastructure determine the amount and structure of tourist movement to the cultural landscape. The presence of tourism therefore engenders some environmental impact on the tourist site as shown in figure 5. But this can be controlled where all stakeholders are responsible for the development and protection of the site.

Nicolaides (2015) posits that tourism stakeholders are those individuals and groups that have a claim or an interest in the tourism plan and activities of a place and also possess the ability to influence those activities in some way. The claim or interest could be in the benefits they get from the industry and they are also influencers because of the contributions they make in the industry. This category of people will also bear the pains or contests which come along with the benefits and opportunities of the site and can therefore not be neglected in the overall decision of the development of the cultural landscape. The stakeholders will stimulate ethical tourism on the site on one hand which will lead to its further development and then the conservation of the cultural landscape and on the other hand, they reap the benefits of tourism beginning from the local community. The involvement of the stakeholders with all their efforts at developing the cultural landscape will eventually result in an exclusive tourist site which will be protected and sustainable.

Conclusively, the interaction between the various strategies of tourism and cultural landscape has be used to effectively develop a tourism framework which can serve as a guide for any cultural landscape development in Nigeria and around the world. It is clear that key stakeholders have a fundamental role to play in advancing the developmental strategies that will promote the sustainable cultural landscape that will be preserved for the future generations. The only way to achieve this is by developing and following strictly a well-planned conservation strategy for the cultural landscape.

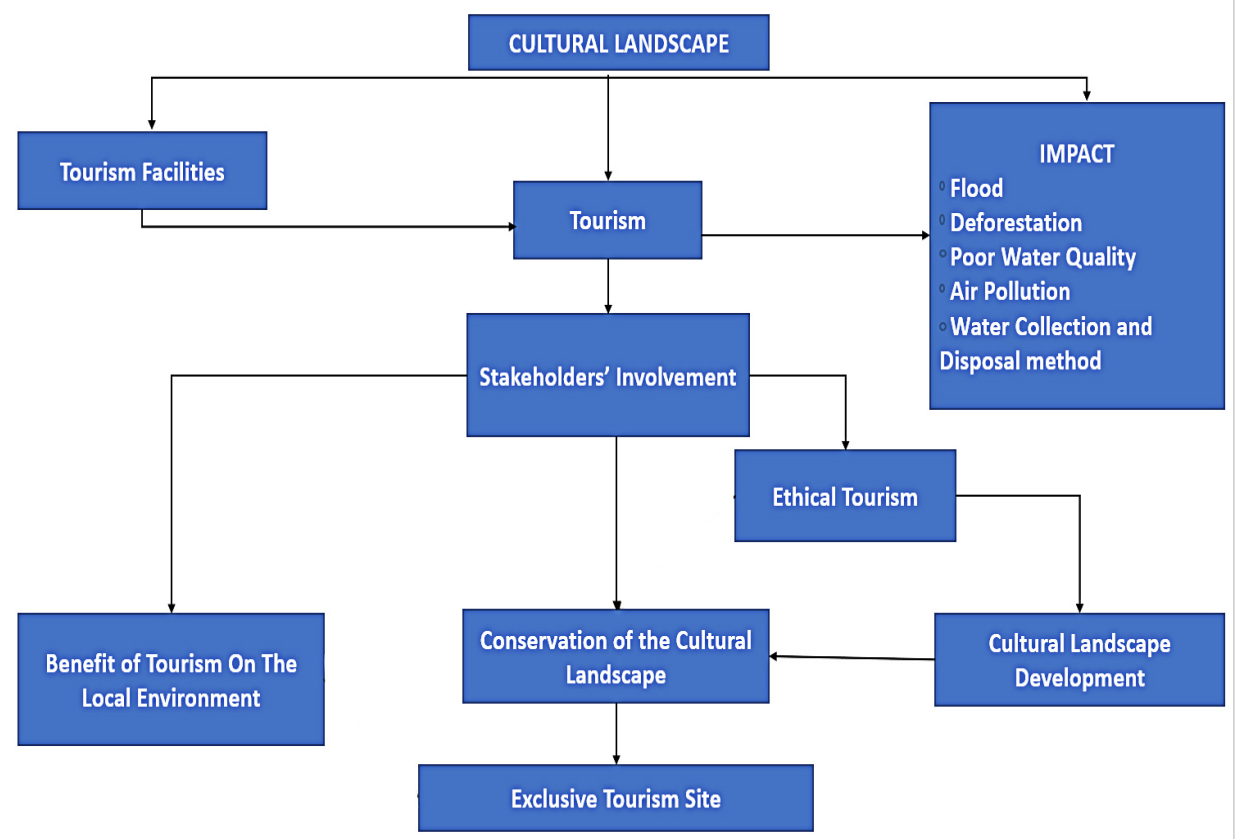

Figure 5: The Cultural Landscape and Tourism Sustainability Framework Source: Author, 2021 


\subsection{Conclusion}

This study has succeeded in reviewing the theoretical issues relating to the development and sustainability of the cultural landscape. Through the literature review of previous models and frameworks such as, General System Theory (Cuervo, 1967), Cultural landscape management framework (2006) Diamond Model for sustainable tourism (2019), and The Ethical tourism model (2008), a conceptual framework for sustainable tourism on the cultural landscape was developed.

The framework developed in this study has been able to combine most essential frameworks and models in tourism which could best fit to developing a cultural landscape. These frameworks and models have considered the social, economic and ecological state of the cultural landscape and the sub and super structures for tourism which will make the site a sought-out place for tourists. This cannot be achieved without the involvement of the stakeholders and in this case the development managers who have the responsibility of ensuring that while the carrying capacity of the destination and local community's satisfaction is considered, the tourists' experiences are all considered while they use the site ethically all in a bid to managing the impacts of tourism on the cultural landscape.

In conclusion, to be able to develop an exclusive tourist destination on a cultural landscape, development of the site with thoughtful attention to conservation by all stakeholders practicing ethical tourism is required. Hence, managing the negative impacts of tourism on a cultural landscape will not only result in pleasant tourists' experiences and the conservation of the cultural landscape, it stands the chance to improve the monuments and sites and will also improve income generation through a well visited touristic site.

\section{References}

Adeyemi, A.A. and Oyinloye, T.H. (2020). Effectiveness of Alternative Conservation Means in Protecting the Osun-Osogbo Sacred Grove in South-West, Nigeria. Plant. 8(1), 2020, pp. 1-9. doi: 10.11648/j.plant.20200801.11

Adillón, R. (2020). Diamond Model: A Theoretical Framework for The Sustainable Development Of Tourism. Art Human Open Acc J. 2019;3(1):11-23. DOI: 10.15406/ahoaj.2019.03.00099

Adhuze, O and Ayeni, D. (2019). River-Based Cultural Landscapes and the Challenges of Flood Disaster in the Tropics. Journal of Environment and Earth Science. www.iiste.org ISSN 2224-3216 (Paper) ISSN 2225 0948 (Online) DOI: 10.7176/JEES. 9(7)

Agbebaku, H. U. (2015) Environmental Challenges and Climate Change: Nigeria Experience. Journal of Research in Environmental and Earth Science. 2(4) pp: 01-12 ISSN(Online): 2348-2532 www.questjournals.org.

Ayeni, D. A. (2012a). Enhancing and Developing Sustainable Tourism Through Landscaping In Nigeria. (Doctoral dissertation, De Montfort University, Leicester, United Kingdom). Retrieved from https://wscholars.com/index.php/ajtr/article/download/194/114.

Beni, M.C. (2001) Análise Estrutural do Turismo, 4th edn. Senac-São Paulo, São Paulo, Brazil.

Benson, E. (2014). Cultural Tourism and Sustainability in Nigeria. Mediterranean Journal of Social Sciences. 5(14) 649-655.

Birnbaum, C.A. (ed.) (1999b). Preserving Modern Landscape Architecture, papers from the Wave Hill-National Park Service Conference. Washington DC. Spacemaker Press

Cuervo, R.S. (1967) El Turismo como Medio de Comunicación Humana. Departmento de Turismo del Gobierno de Mexico, Mexico City

Dalat, G. (2010). Developing rural based tourism as a strategy for rural development in Nigeria. International journal of creativity and technical development. 2(1)1-3.

Diminyi, C. A., \& Okpoko, P. U. (2017). Integrating traditional conservation mechanisms into modern management of ecotourism resources in Okwangwo Division of Cross River National Park. Journal of Tourism and Heritage Studies, 61, 81-93. https://doi. org/10.33281/JTHS20129.2017.6.2.7

Ejikeme, J.N., Okpoko, P.U., Okpoko, C.C. and Diminyi, C.A. (2020) Preservation and conservation of Cross River Monoliths for tourism development. Cogent Arts \& Humanities, 7:1, 1812182, DOI: $10.1080 / 23311983.2020 .1812182$

Fadamiro, J. A., \& Adedeji, J. A. (2015). Cultural Landscapes of the Yoruba of South-Western Nigeria Demystified as Solidified Time in Space. Space and Culture, 19(1), 15-30. doi:10.1177/1206331215595751

Fennell D. (2014) Ethics, Tourism. In: Jafari J., Xiao H. (eds) Encyclopedia of Tourism. Springer, Cham. https://doi.org/10.1007/978-3-319-01669-6_74-1

GhulamRabbany, M. D; Sharmin A; Airin R; Faijul I, and Fazlul H. (2013) Environmental Effects of Tourism. American Journal of Environment, Energy and Power Research. 1(7), PP: 117-130, ISSN: 2329-860X (Online) Available online at www.ajeepr.com.

Haenraets, J. (2009). Identifying key problems regarding the conservation of designed landscapes: landscapes of the recent past. (Doctoral dissertation). De Montfort University, Leicester, United Kingdom. 
Hamzah, J., Habibah, A., Buang, A., Jusoff, K. Toriman, M.E., Mohd Fuad, M.J., Er, A.C. and Azima, A.M. (2012). Flood Disaster. Impacts and the Tourism Providers' Responses: The Kota Tinggi Experience. Advances in Natural and Applied Sciences, 6(1), 26-32.

Isife, C. T. (2012) Environmental Problems in Nigeria - A Review. Sustainable Human Development Review. Vol. 4, Nos. 1\&2, 21-38

IUCN (1996). The World Conservation Union, Tourism, Ecotourism and Protected Areas.

Jakulin, T.J. (2017). Systems Approach to Tourism: A Methodology for Defining Complex Tourism System. Organizacija, 50: 3. DOI: 10.1515/orga-2017-0015

Jiboku, J. and Jiboku, P. (2010). Harnessing tourism potentials in Nigeria for national development. Journal of Resources and National Development. 8(1) 14-22

Johnson, V. (1992). "What is Environmental Education" in Michael Atchia (ed) "Environmental Education in the African School Curriculum", Ibadan; African Curriculum Organization.

Kirdsiri, K. (2011). Cultural landscape and vernacular architecture in the historic town of Keng Tung, Shan State, Myanmah.(Doctoral dissertation) Silpakon University, Bangkok, Thailand.

Koncul, N. (2008). Environmental Issues and Tourism. International Journal of Aromatherapy, 13(2- 3), 63-64. https://doi.org/10.1016/S0962-4562(03)00084-5

Leach, E. R. (2000). Political system of Highland Burman London; African Civilization; Origin, growth and development, UTO Publications.

Lohmann, G. and Panosso Neto, A. (2017). Tourism theory : concepts, models and systems. Wallingford, Oxfordshire, UK : CAB International.

Lovelock, B. and Lovelock, K.M. (2013) The Ethics of Tourism: Critical and Applied Perspectives. Routledge, London.

Mehta, P. (2013). Tourism and consequential environmental degradation: An unfolding equation of impacts in Indian context. Review Article Acta de Gerencia Ciencia 1(3) pp 1- 9 www.cagena.com

Milan, S.B. (n.d) Cultural Landscapes: A Framework for Their Holistic Management.

Molina, S. (1997) Turismo: Metodología parasu Planificación. Trillas, Mexico City

Muoghalu, L.N. (2004). "Environmental Problems and their Effects on Human Life: From Awareness to Action." In H.C. Mba et al (eds.), "Management of Environmental Problems and Hazards in Nigeria", Hants: Ashgate Publishing Ltd.

Nora P, Mechtild M, and Pierre-Marie, R. (2009). World Heritage Cultural Landscapes, Handbook for Conservation and Management. Paris: UNESCO.

Nwankwo, E.A (2015). Developing Heritage Tourism in Imo State, Nigeria: Socio-Economic and Cultural Gains. Journal of Tourism, Hospitality and Sports. 3(1). www.iiste.org

Ojo, J. (2014). Managing tourism for socio-economic development in Nigeria local government: A case of Idanre Local Government. Journal of African Studies and Development, 6(2) 29-35

Onyima, B.N. (2016). Nigerian cultural heritage: preservation, challenges and prospects. in OGIRISI a New Journal of African Studies. Vol. 12. 273-292

Speed, C. (2008) Are backpackers ethical tourists? In Hannam, K. and Atelievic, I. (eds) Backpacker Tourism: Concepts and Profiles. Channel View Publications, Bristol, UK, pp. 54-81.

Sunlu, U. (2003). Environmental impacts of tourism. In: Camarda D. (ed.), Grassini L. (ed.). Local resources and global trades: Environments and agriculture in the Mediterranean region. p. 263-270

Tunde, M. (2012). Harnessing tourism potentials for sustainable development: A case of Owu Water Falls in Nigeria; Journal of sustainable development in Africa. 14(1) 119-133.

Vicens, M. (2017). Tourism Saturation Data: the summer population grows at a path of 33\%. Diario de Mallorca.

UNESCO (2008). Operational Guidelines for the Implementation of the World Heritage Convention. Paris, World Heritage Centre.

World Heritage Centre (WHC), 2008, Operational Guidelines for the Implementation of the World Heritage Convention. Retrieved from www.unesco.org. assessed $27^{\text {th }}$ July, 2019

Timothy, D. J. (2011). Cultural and heritage tourism: An introduction. Channel View Publications.

Tosun, C. (2001). Challenges of sustainable tourism development in the developing world: The case of Turkey. Tourism Management, 22(3), 289-303. https://doi.org/10.1016/S0261-5177(00)00060-1 